\title{
Effects of wetting rate and simulated rain duration on soil crust formation of red loam
}

\author{
Yuguo Han ${ }^{1}$ Yuntao $\mathrm{Fan}^{2} \cdot$ Zhongbao Xin $^{1} \cdot$ Lei Wang ${ }^{3} \cdot$ Qiangguo $\mathrm{Cai}^{4}$ • \\ Xiangyu Wang ${ }^{5}$
}

Received: 10 November 2014/ Accepted: 8 August 2015/Published online: 6 January 2016

(C) Springer-Verlag Berlin Heidelberg 2015

\begin{abstract}
The characteristics of crusts are closely related to soil erosion in red loam under a rainfall condition. To better manage crust-prone soils and to accurately predict hydrological processes, it is necessary to understand the mechanism of crust formation. Wetting rate is an important factor influencing soil aggregate stability and crust formation. In this study, we considered two factors, wetting rate (slow $2 \mathrm{~mm} \mathrm{~h}^{-1}$, fast $50 \mathrm{~mm} \mathrm{~h}^{-1}$ ) and rainfall quantity (intensity of $60 \mathrm{~mm} \mathrm{~h}^{-1}$ with every $5 \mathrm{~min}$ as a treatment from 0 to $60 \mathrm{~min}$ ). The results show that soil in the fast wetting treatment had higher bulk density, stronger crust strength and lower infiltration rate. Therefore, the fast wetting treatment had higher ability to resist the damage caused by raindrops and to resist soil erosion, and higher runoff rate than slow wetting treatment. Crust formationdestruction-formation process appeared sharp in fast wetting treatment but gentle in slow wetting treatment. Surface morphology and profile microstructure show that crusts were formed earlier in fast wetting treatment. The
\end{abstract}

Zhongbao Xin

xinzhongbao@126.com

1 School of Soil and Water Conservation, Key Laboratory of Soil and Water Conservation and Desertification Combating, Ministry of Education, Beijing Forestry University, Beijing 100083, China

2 Chinese Academy of Agricultural Mechanization Sciences, Beijing 100083, China

3 Landscape Architecture School, Beijing Forestry University, Beijing 100083, China

4 Institute of Geographic Sciences and Natural Resources Research, Chinese Academy of Sciences, Beijing 10010, China

5 Fangshan District, Beijing Water Authority, Beijing 102442, China aggregates in slow wetting treatment had higher stability than those in fast wetting treatment. The crust strength of the soil pretreated by slow wetting was weaker than that in fast wetting case due to the persistent presence of stable aggregates, albeit microaggregates, and, consequently, reduced levels of compaction.

Keywords Wetting rate $\cdot$ Cumulative rainfall $\cdot$ Soil surface strength $\cdot$ Micromorphological picture $\cdot$ Soil crust

\section{Introduction}

Red loam soils are included within the Ferralosols order according to the Chinese Soil Taxonomy (mainly Kandiudults, Paleudults and Kanhapludults according to the US Soil Taxonomy and Orthic Acrisols according to the World Reference Base for Soil Resources, WRB) (Cooperative Research Group on Chinese Soil Taxonomy 2001; Buol et al. 2011; FAO 1998). In general, red loam has good physical conditions for plant growth though it often has very low water-holding capacity. Red loam is widely distributed in the world: nearly $50 \%$ of the total land is red loam in South America, $29 \%$ in Africa, $25 \%$ in Australia, and $21 \%$ in Asia (Fan et al. 2005; Hartemink et al. 2010). In China, red loam soil is mainly distributed in south to the Yangtze River, and the majority is distributed in Guangdong, Guangxi, Fujian, Taiwan, Jiangxi, Hunan, Yunnan, and Guizhou, followed by Hubei, Sichuan, Zhejiang, and Anhui. Due to frequent rainfall events, red loam-dominated regions are frequently affected by soil erosion (Narayana and Babu 1983; Kumar 2003).

Soil crusts are a surface layer of soil that becomes harder than the underlying horizon, and they can be divided into physical crusts (the crust in this study is physical crust) 
and biological crusts. Soil surface physical crust formation is a common phenomenon in soils exposed to rain (McIntyre 1958). Crust formation results in lower infiltration rate and higher runoff rate, thereby inducing soil erosion (Morin and Winkel 1996; Nciizah and Wakindiki 2014). To better manage the crust-prone soils and to accurately predict the hydrological processes, it is necessary to understand the mechanism of crust formation and its effects on the relevant hydraulic characteristics (Bissonnais and Arrouays 1997; Pathak et al. 2013).

The tendency of a soil to form a crust depends on aggregate stability (Eltaif and Gharaibeh 2008). Aggregate stability, which is a measure of the resistance of aggregates to breakdown, has been found to increase with organic matter, clay, and sesquioxides content (Eldridge and Leys 2002). Levy and Mamedov, in a study on slaking of six soils differing in clay content, reported that aggregate stability was relatively lower for coarse- and mediumtextured soils ( $<25 \%$ clay) with low organic matter contents (Levy and Mamedov 2002). Conversely, aggregate stability was found to be higher in finer textured soils due to the fact that the clay and organic matter act as cementing and binding agents in the soil (Kemper and Koch 1966). Loch demonstrated that aggregate disintegration depended on the wetting rate (WR) at which the initial dry aggregates were wetted, and was an energetically more important process than the impact of the raindrops (Loch 1994). Loch also emphasized the importance of WR in aggregate disintegration and seal formation in stable soils with high clay content, whereas Agassi et al. and Betzalel et al. stressed the role of raindrop kinetic energy in seal formation in less stable sandy loam soils having low organic matter content (Agassi et al. 1985; Betzalel et al. 1995). Thus, the degree of aggregate disintegration of soil surface is determined by $\mathrm{WR}$, raindrop impact energy, the electrolyte concentration of the soil solution (e.g., Exchangeable Sodium Percentage, ESP), and aggregate stability (Shainberg and Levy 1992).

Crusts, formed as a result of aggregate disintegration and compaction during a rain or irrigation event, have higher shear strength, greater bulk density, finer pores, and lower infiltration rate than the underlying soil (Bradford et al. 1987; Bradford and Huang 1992). Declining infiltration rate and higher runoff amount have been the most frequently monitored properties to determine the degree of crust formation (Moore 1980; Shainberg et al. 2003). Some studies have used measurements of soil surface strength to assess the degree of crust formation (Assouline 2004; Luk and Cai 1990). Crust formation has also been directly observed in micromorphological studies (Norton 1987; Chen et al. 1980). The scientific literature shows that the dynamics of crust formation and the temporal changes in surface sealing are not fully documented. In this study, a laboratory study conducted on repacked soil samples, proposes the following objectives: (1) to evaluate the effect of WR on crust formation under simulated rain conditions considering properties such as penetrometer depth (discussed later), bulk density, rainfall cumulative infiltration and aggregate size distribution; (2) to investigate the process and characteristics of the crust formation in red loam exposed to rain; and (3) to explore the changes in crust strength and micromorphology in terms of different wetting rates and different rain durations.

\section{Materials and methods}

\section{Experiment design}

In this study, we considered two factors, wetting rate and rainfall quantity (with the same intensity and in various rainfall durations). There were two wetting rates, a slow one $\left(2 \mathrm{~mm} \mathrm{~h}^{-1}\right)$ and a fast one $\left(50 \mathrm{~mm} \mathrm{~h}^{-1}\right)$. Rainfall was simulated artificially in an intensity of $60 \mathrm{~mm} \mathrm{~h}^{-1}$ with every $5 \mathrm{~min}$ as a treatment from 0 to $60 \mathrm{~min}$. Factors and levels were cross-experimented. Therefore, there were a total of 24 treatments. Penetration experiment was conducted once every day in four repetitions and lasted 17 days. Bulk density and accumulation were measured after the corresponding process in four repetitions. Morphology and profile microstructure were collected in 5, 30 and $60 \mathrm{~min}$ in three repetitions.

The crusts were studied in cups. Soils in the cups were also prewetted in our study at a rate of either $2 \mathrm{~mm} \mathrm{~h}^{-1}$ for slow wetting or $50 \mathrm{~mm} \mathrm{~h}^{-1}$ for fast wetting. Rainfall simulations were done above cups and lasted $60 \mathrm{~min}$. To precisely observe the crusting process, the cups were collected and removed group by group at interval of $5 \mathrm{~min}$, i.e., at 5, 10, $15 \mathrm{~min}$, etc., and finally at $60 \mathrm{~min}$.

\section{Soil for testing}

We selected red loam for this study from Xianning City, Hubei Province in China. The climate is subtropical monsoon and the mean annual temperature is $15^{\circ} \mathrm{C}$. The average annual rainfall is about $1300 \mathrm{~mm}$, unevenly distributed, and mainly occurs between April and July. The area is mainly covered by forest land and grass land, followed by cultivated land. The sample soil is selected from the sloping cultivated land.

Samples were collected from the upper layer (depth $0.02 \mathrm{~m}$ ) of a cultivated field at 5 different sites and then mixed to have a composite sample in May 2012. Soil physical and chemical properties were determined by standard methods with 5 replications (United States Department of Agriculture 1996): particle size analysis by the pipette method (Alary et al. 2013), cation exchange 
Table 1 Selected physical and chemical properties of red loam

\begin{tabular}{|c|c|c|c|c|c|c|c|}
\hline \multicolumn{3}{|l|}{ Texture } & \multirow{2}{*}{$\begin{array}{l}\text { CEC } \\
\left(\mathrm{mmol} \mathrm{kg}^{-1}\right)\end{array}$} & \multirow[t]{2}{*}{$\operatorname{ESP}(\%)$} & \multirow{2}{*}{$\begin{array}{l}\mathrm{OM} \\
\left(\mathrm{g} \mathrm{kg}^{-1}\right)\end{array}$} & \multirow{2}{*}{$\begin{array}{l}\mathrm{CaCO}_{3} \\
\left(\mathrm{~g} \mathrm{~kg}^{-1}\right)\end{array}$} & \multirow{2}{*}{$\begin{array}{l}\text { Field bulk density } \\
\left(\mathrm{kg} \mathrm{m}^{-3}\right)\end{array}$} \\
\hline $\begin{array}{l}\text { Sand } \\
(2-0.02 \mathrm{~mm}, \%)\end{array}$ & $\begin{array}{l}\text { Silt } \\
(0.02-0.002 \mathrm{~mm} \text {, } \\
\%)\end{array}$ & $\begin{array}{l}\text { Clay } \\
(<0.002 \mathrm{~mm}, \\
\%)\end{array}$ & & & & & \\
\hline $4.7 \pm 0.1$ & $71.2 \pm 0.5$ & $24.1 \pm 0.4$ & $173 \pm 4$ & $0.51 \pm 0.01$ & $16.2 \pm 0.3$ & $98 \pm 2$ & $(1.15 \pm 0.03) \times 10^{3}$ \\
\hline
\end{tabular}

\pm standard deviation, 5 replications, $n=5$

$C E C$ cation exchange capacity, $C E C$ exchangeable Na percentage, $O M$ organic matter

capacity by the NaOAc method (Wang et al. 2005), exchangeable $\mathrm{Na}$ by the NH4OAc method (Cresswell and Hamilton 2002), organic matter content by wet combustion (Adriano 2001), and field bulk density by cutting ring method (Grossman and Reinsch 2002). Selected properties of the soil are presented in Table 1.

Soil samples were air dried, sieved $<2 \mathrm{~mm}$, and packed to a bulk density of $15 \times 10^{3} \mathrm{~kg} \mathrm{~m}^{-3}$, into cups. The bulk density was similar to that of the soil in the field. The cups, similar to those described by Morgan (1978), had a crosssectional area of $78.5 \mathrm{~cm}^{2}$ and a depth of $2.5 \mathrm{~cm}$ but were modified by the addition of a narrow slot, $7 \mathrm{~mm}$ wide, around the lower side of the cup to facilitate infiltrated water drainage.

\section{Wetting device}

The wetting device consisted of cups, a moisturizer and a Marriott bottle. Several holes were evenly distributed at the bottom of the cup for water intake and drainage. The water outflow was controlled by the Marriott bottle. The soils in the cups were wetted from the bottom with deionized water at a rate, controlled by a Marriott bottle, of either $2 \mathrm{~mm} \mathrm{~h}^{-1}$ for slow wetting or $50 \mathrm{~mm} \mathrm{~h}^{-1}$ for fast wetting. Considering that soil cups would be flooded if runoff could not be discharged in time, the cups were placed under the rainfall simulator at a slope of $5^{\circ}$ to prevent excessive ponding of water.

The samples were then exposed to the simulated rainfall.

\section{Rainfall simulation experiment}

A 60 min rainfall event was simulated at an intensity of $60 \mathrm{~mm} \mathrm{~h}^{-1}$ under a hydraulic pressure of $0.08 \mathrm{MPa}$ from downward-facing Spraco full cone nozzles (Spraco Inc., Nashua, NH) at a drop fall height of $4.57 \mathrm{~m}$. The average droplet diameter was $1.44 \mathrm{~mm}$. Water having an electrical conductivity of $0.2 \mathrm{dS} \mathrm{m}^{-1}$ and a $\mathrm{Na}$ adsorption ratio of 2 was used for the simulation. The kinetic energy of the raindrops, $e$, was calculated with the following equation proposed by Brown and Foster (1987):

$e=0.29[1-0.72 \exp (-0.05 i)]$, where $i$ is rainfall intensity $\left(\mathrm{mm} \mathrm{h}^{-1}\right)$. Thus, the kinetic energy of the rainfall was $27.96 \mathrm{~kJ} \mathrm{~m}^{-3}$.

\section{Crust strength measured with a penetrometer}

A standard fall-cone penetrometer (Campbell 1976) was used to determine the soil surface strength immediately after the cups were removed from the rainstorm and periodically thereafter as the samples air dried (Al-Durrah and Bradford 1981). A group of 34 cups were selected at random at interval of $5 \mathrm{~min}$ and then air dried in the laboratory. This experiment was conducted for 17 days. During the experiment, the conical tip of the penetrometer fell into a point within the soil and remained for $3 \mathrm{~s}$, and the readings were recorded. Four points were selected for the measurement, and the average of these measurements was used as the final reading. Gravimetric soil moisture contents were determined for a small amount of soil, removed with a spoon from the penetration points used for the readings immediately following that procedure. Each of the cups collected after a particular rain duration was used for the soil strength and moisture content measurements during different stages of the air-drying process, thus enabling soil strength to be plotted as a function of moisture content. The exponential regression between penetrometer readings and soil moisture content found by Luk and Cai in loess soil samples from Wangjiagou, Lishi, China was used (Luk and Cai 1990):

$P=a e^{b \theta}$,

where $P$ is penetrometer reading $(\mathrm{mm}), \theta$ is gravimetric soil moisture content (\%), and $a$ and $b$ are regression coefficients (Luk and Cai 1990; Asadi et al. 2007).

Crust strength was determined from the penetrometer reading using the method of Luk and Cai (1990):

$\tau=K\left(Q / P^{2}\right)$,

where $\tau$ is shear strength of the crust (Pa), $Q$ is mass of the fall cone $(\mathrm{g})$, and $K$ is a proportional coefficient related to soil texture (Towner 1973). For a given cone mass and the same soil under measurement, the following holds: 
$\tau \propto 1 / P^{2}$.

Therefore, $1 / P^{2}$ is an index that characterizes crust strength. Thus, regression equation (Eq. 2) for the rainfall event was used to estimate penetrometer depths at soil water content of $20 \%, P_{20}^{2}$, from which the crust strength index was computed (Eqs. 3, 4).

\section{Bulk density and cumulative infiltration}

Four cups were selected at random at interval of $5 \mathrm{~min}$ during the rainfall event to collect soil samples from the surface layer $(3 \mathrm{~mm})$ to calculate the bulk density from their mass and volume. The volume is determined by coating the samples with a water-repellent substance and by weighing it first in air, then again while immersed in a liquid of known density (Saleh 1993; Cheng 1990). A total of 48 cups of soil samples were measured for bulk density. Each of the samples was measured four times, and the measured values were averaged. A plastic bag was attached to the bottom of each cup to collect the infiltrated water during rainfall. After the cups were collected from rainfall, the plastic bag was removed and the volume of the water in it was measured with a measuring cylinder.

\section{Aggregate stability determination}

Before starting the experiment, microaggregate stabilities were measured by the dry and wet sieving methods (Zhang and Horn 2001). Air-dried soil samples were sieved by hand on a stack of five sieves: 5-, 2-, 1-, 0.5-, and 0.25-mm mesh size. The mass percentage of each size fraction was calculated and, based on these percentages, composite soil samples were prepared for wet sieving. Each composite $50 \mathrm{~g}$ sample was placed in a flask and wetted slowly by spraying with deionized water until saturated. Finally, the soil samples were placed on the same stack of sieves used for dry sieving, which were then immersed in water and raised and lowered 3-4 cm under the water surface at a speed of 30 cycles $\min ^{-1}$. The material remaining on each sieve was oven dried and weighed to determine the water-stable aggregate mass. Mean weight diameter (MWD) was calculated and used to quantify aggregate stability (Table 2).

\section{Surface morphology and profile microstructure}

For micromorphological analysis (Wakindiki and Ben-Hur 2002), which permits direct observation of the changes in the soil surface structure, the air-dried soils in the cups were impregnated with epoxy resin, dried, cured and thin sectioned from the top of the crust to a thickness of about $30 \mu \mathrm{m}$. The thin section was glued onto the microscope slides with Canada balsam and then placed under a polarizing microscope (Nikon Optiphot 2-POL).

Profile microstructure of both fast and slow wetting treatments in three rainfall durations was observed. Each treatment had three samples, i.e., a total of 18 samples, for this observation. Each sample was thin sectioned to obtain the top of the crust for surface morphology. The most representative one was selected from the micrographs for each treatment.

\section{Statistical analysis}

The relationship between penetrometer reading and soil moisture content was drawn with Office Excel 2007. A fitting formula was derived to calculate $P_{20}\left[P_{20}\right.$ is penetrometer reading $(\mathrm{mm})$, when gravimetric soil moisture content is $20 \%$ ] to indicate soil strength index. The readings of penetrometer depth in 5, 30 and 60 min were analyzed. The relationship between bulk density and cumulative infiltration was also drawn with Office Excel 2007. MWD was calculated using formula: MWD $=\frac{\sum_{i=1}^{n}\left(\bar{R}_{i} \times W_{i}\right)}{\sum_{i=1}^{n} W_{i}}$, where MWD is mean weight diameter, $R_{i}$ is mean diameter of the aggregates within any grain size, and $W_{i}$ is dry weight of the aggregates corresponding to $R_{i}$. Significance analyses in this study were all made using SAS Version 8.0 (SAS Inst., Cary, NC).

\section{Results and discussion}

\section{Crust strength}

Penetrometer readings of the crusts, taken during the drying process, as a function of soil moisture content are

Table 2 Aggregate size distribution and aggregate stability parameters

\begin{tabular}{lllllll}
\hline Method & \multicolumn{2}{l}{ Aggregate size distribution (\%) } & & \multicolumn{2}{c}{ MWD (mm) } \\
\cline { 2 - 6 } & $5-2 \mathrm{~mm}$ & $2-1 \mathrm{~mm}$ & $1-0.5 \mathrm{~mm}$ & $0.5-0.25 \mathrm{~mm}$ & $<0.25 \mathrm{~mm}$ \\
\hline Dry sieving & $14.57 \pm 0.18$ & $27.53 \pm 0.21$ & $24.94 \pm 0.13$ & $17.97 \pm 0.20$ & $15.00 \pm 0.11$ & $1.20 \pm 0.04$ \\
Wet sieving & $2.46 \pm 0.09$ & $13.03 \pm 0.15$ & $21.88 \pm 0.51$ & $21.21 \pm 0.44$ & $41.42 \pm 1.97$ & $0.58 \pm 0.01$ \\
\hline
\end{tabular}

MWD of soil aggregates was measured also after slow and fast wetting treatments

\pm Standard deviation, 4 replications, $n=4$ 
Fig. 1 Penetrometer depth $(\mathrm{mm})$ reading as a function of soil moisture content (\%) and duration of rainfall, for crust on soil pretreated by fast wetting $\left(50 \mathrm{~mm} \mathrm{~h}^{-1}\right)$ and slow wetting $\left(2 \mathrm{~mm} \mathrm{~h}^{-1}\right)$. Each data shows the means of four replicates, and the error bar represents the standard error
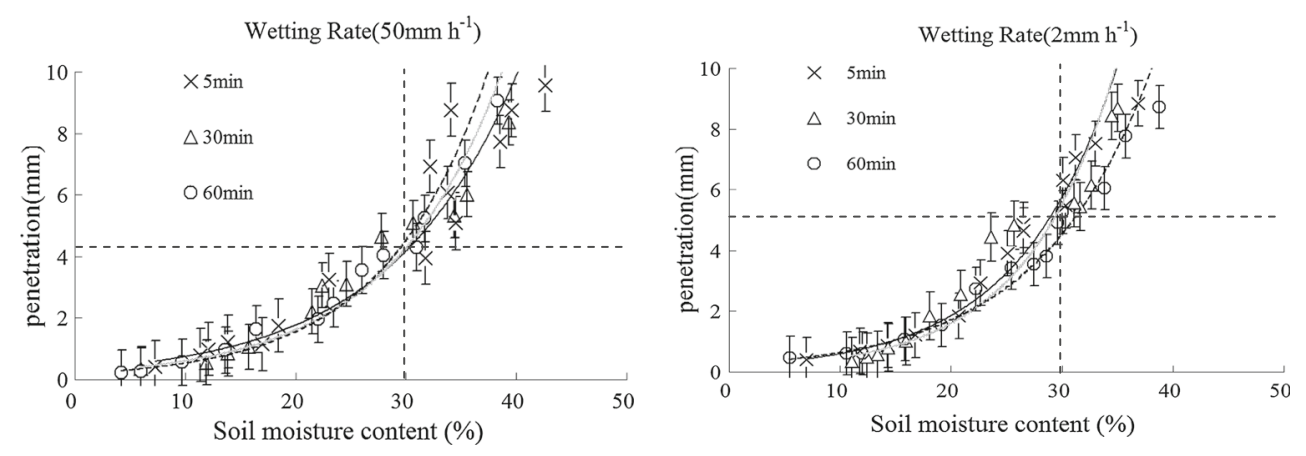

Table 3 Exponential relationship between penetrometer depth, $\mathrm{P}(\mathrm{mm})$, and soil moisture content, $\theta(\%)$

\begin{tabular}{lllllll}
\hline Fast wetting $\left(50 \mathrm{~mm} \mathrm{~h}^{-1}\right)$ & & & Slow wetting $\left(2 \mathrm{~mm} \mathrm{~h}^{-1}\right)$ & \\
\cline { 1 - 1 } Rainfall duration $(\mathrm{min})$ & Fitting equation & $R^{2}$ & & Rainfall duration $(\mathrm{min})$ & Fitting equation & $R^{2}$ \\
\hline 5 & $P=0.3188 e^{0.0859 \theta}$ & 0.95 & 5 & $P=0.1955 e^{0.1127 \theta}$ & 0.98 \\
30 & $P=0.2293 e^{0.0976 \theta}$ & 0.95 & 30 & $P=0.1355 e^{0.1236 \theta}$ & 0.93 \\
60 & $P=0.183 e^{0.1069 \theta}$ & 0.97 & 60 & $P=0.2423 e^{0.0976 \theta}$ & 0.98 \\
\hline
\end{tabular}

presented in Fig. 1. The graphs indicate that crust strength, inversely related to the depth of cone penetration, increased with drying. With the soil moisture content of $30 \%$ as an example, penetrometer depth was smaller in the fast wetting treatment than in the slow wetting treatment. By fitting the exponential relationship between penetrometer depth, $\mathrm{P}$, and soil moisture content, $\theta$, at different wetting rates (Table 3), the penetrometer depth with respect to different soil moisture contents at 5,30 and 60 min was calculated. In the treatment of different wetting rates, the difference in penetrometer depth was 5.43-87.23\% with the same rainfall duration and the same soil moisture content. Wetting rate, as an influence factor, was statistically significant at the 0.05 probability level, indicating that it had significant effect on penetrometer depth.

The soil surface strength is determined by the cohesion force between soil particles and the internal friction in soil particles. As shown in Fig. 1, increase of penetration depth is linked to increasing soil moisture content, indicating that cohesion force and internal friction were decreased with increase in soil moisture content, which is caused by water dissipation (a phenomenon that when drier soil aggregates are dripped water, their structure will be broken and become loose fine particles). Slaking effect caused by water on aggregates became more significant with the increase in wetting rate.

The burst of large aggregates resulted in microaggregates and smaller fine particles. Due to lubrication of water and gravity of soil particles, soil particles were more closely arranged, and the porosity was reduced, thereby increasing the soil surface strength. The anti-shear capacity of microaggregates and fine particles was enhanced under lower moisture content, thereby speeding up the growth rate of the soil surface strength (Eldridge and Greene 1994).

Soil strength index, $1 / P_{20}^{2}$, shows a similar trend in the two treatments in Fig. 2. In the fast wetting treatment, there were three peaks. In the slow wetting treatment, crust strength did not change significantly during 0-20 min but had two fluctuations later, which was related to a large amount of aluminum oxide and iron oxide in red loam that act as cementing agent of soil particles and effectively improve the stability of aggregates. Soil aggregates were destructed as the rainfall gradually increased until reaching a threshold, and finally the original soil crusts were destroyed. This represented a crust formation-destruction process. Then, the crust would be formed again and the next formation-destruction process began.

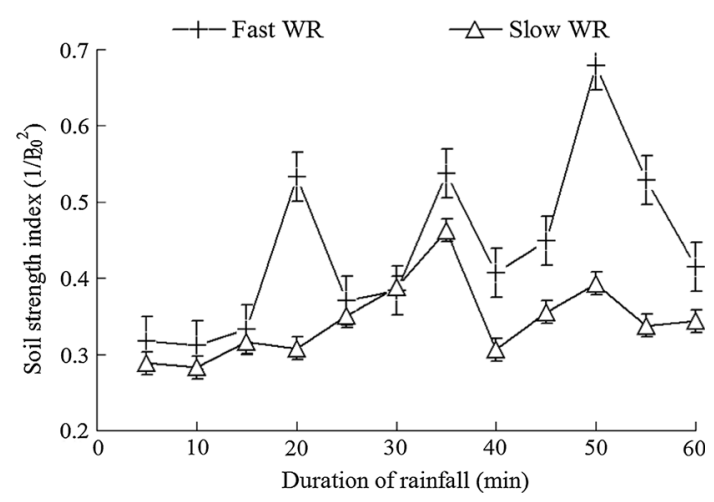

Fig. 2 Soil strength index as a function of duration of rainfall and wetting rate. Each data show the means of four replicates, and the error bar represents the standard error 
In earlier rainfall course, unstable crusts were formed earlier in the fast wetting treatment than in the slow wetting treatment because the fast wetting had more significant effect on aggregates, while in later rainfall course, the trend of crust formation tended to be similar.

Throughout the rainfall course, soil surface strength index fluctuated more widely in the fast wetting treatment than in the slow wetting treatment. That is to say, crust formation-destruction-formation process appeared sharp in the fast wetting treatment but gentle in the slow wetting treatment. This shows that the crusts in the fast wetting treatment had higher hardness and thus had higher ability to resist the damage caused by raindrops, and once the damage occurred, the crusts would enter the next round of formation-destruction process. In contrast, the crusts in the slow wetting treatment had lower ability to resist the damage, and thus their formation-destruction process was slower than those in the fast wetting treatment.

Harder crusts required more energy to be destructed, so they could inhibit soil erosion. Imagining a uniform crust formed on the surface of an absolutely uniform slope, the harder the crust is, the smaller the possibility of occurrence of soil erosion is. That is why the fasting wetting treatment in this study had higher ability to inhibit soil erosion. However, most slopes in reality are uneven. In a rainfall event, the crusts with higher strength have lower infiltration rate and will inevitably lead to greater runoff. The runoff will erode firstly the soil with no crusts or crusts having lower strength on the slope. As rainfall lasts, rill erosion occurs and erosion gullies are formed and finally develop into severe soil erosion. Therefore, it is controversial whether crusts facilitate or inhibit soil erosion (Lesschen et al. 2007).

\section{Surface morphology and profile microstructure}

Figure $3 \mathrm{a}$ shows that crusts were formed with increase in cumulative rainfall, but there still were a large number of aggregates and sand gravels that remained to the end of rainfall course. This appeared as surface "coarsening" phenomenon. Crusts developed earlier and more mature in the fast wetting treatment than in the slow wetting

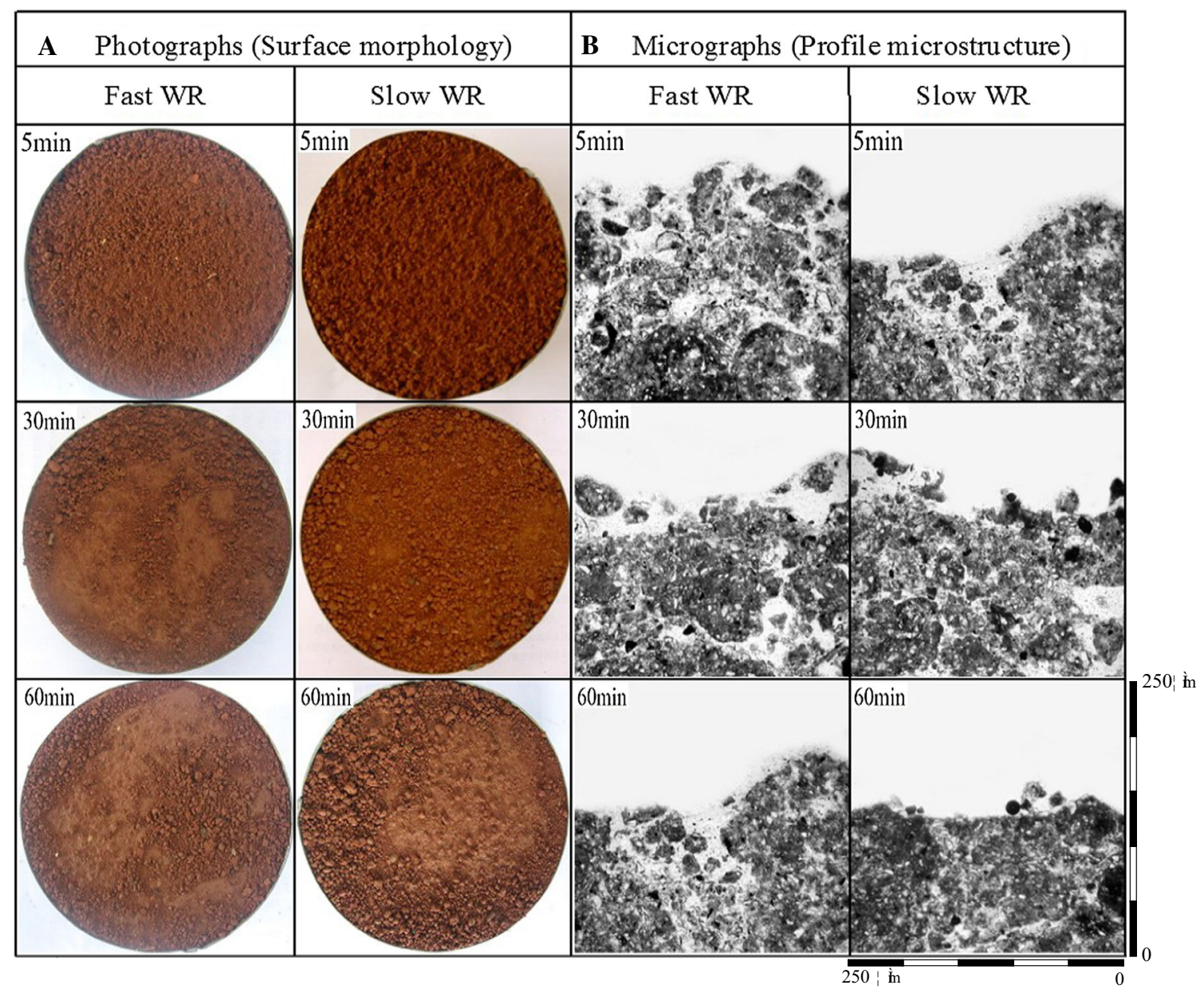

Fig. 3 Photographs and micrographs of soil in different rainfall durations 
treatment, which is corresponding to the trend of soil surface strength index. From Fig. 3a, it can be found that crusts were formed in $30 \mathrm{~min}$ on the surface of the fast wetting treatment. This suggests that crusts were formed easier in the fast wetting treatment. During the rainfall course, the earlier the crusts were formed, the earlier the soil provided the crusts with ability to resist erosivity.

The profile and the surface had similar micromorphology (see Fig. 3b). In earlier rainfall course, the surface in both treatments had large aggregates. After $30 \mathrm{~min}$ of rain, formation of instable crusts was observed in both treatments, and in the surface, there were still a large number of stable microaggregates remaining. To the end of rain, crusts developed were more mature, but there were still some microaggregates in soil surface. Therefore, these pictures of micromorphology well support the analysis of crust strength index.

\section{Soil bulk density and rainfall cumulative infiltration}

Figure 4a shows that bulk density of surface soil increased with rainfall duration, but the rate of increase gradually slowed down and tended to be stable to the end of the rain. The change of bulk density with rainfall duration had similar trend in two different wetting rates. Within the same rainfall duration, bulk density was higher in the fast wetting treatment than in the slow wetting treatment, but this difference became smaller as the rain lasted, suggesting that the effect of wetting rate on surface bulk density is becoming weaker due to soil compaction by raindrop impact. At $60 \mathrm{~min}$, bulk density had increased 10.43 and $9.57 \%$, and porosity decreased 3.96 and $3.59 \%$ in the fast wetting treatment and the slow wetting treatment, respectively.

According to Fig. 4b, infiltration capacity of red loam could be divided into three phases: the first 30 min during which cumulative infiltration volume increased but infiltration rate changed slightly; 30-45 min during which infiltration rate dropped significantly and cumulative infiltration volume increased slowly as soil pores were blocked, that is, water infiltration was obstructed due to the formation of crusts; and 45-60 min during which infiltration rate increased rapidly to that of the earlier rainfall course, indicating that the factors obstructing water infiltration had been eliminated and a new process of crust formation began, which is consistent with the phenomenon of crust formation-destruction-formation process in a rain event proposed by many other researchers (Fan et al. 2008; Hu et al. 2012). Wetting rate had no significant effect on cumulative infiltration volume in earlier and end of rainfall course. During 30-40 min, the slow wetting treatment had higher cumulative infiltration volume and infiltration rate than the fast wetting treatment, indicating that fast wetting rate had slightly higher effect on dispersion of red loam aggregates than slow wetting rate.

Many studies have proven that the raindrops hit the ground, soil crusts are destructed and dissipated, fine particles are dispersed into the soil pores, leading to reduced porosity, increased soil bulk density and decreased infiltration rate, and finally a compaction layer with a great bulk density, that is, crust, is formed (McIntyre 1958; Kemper and Koch 1966; Morin and Winkel 1996). In this study, bulk density increased faster in the fast wetting treatment than the slow wetting treatment, so porosity is smaller and soil infiltration rate is lower in the fast wetting treatment. In fast wetting treatment, higher bulk density coincided with higher crust hardness and lower cumulative infiltration. The ability to resist soil erosion and increase runoff rate in the fast wetting treatment is higher than that in the slow wetting treatment.

\section{Aggregate size distribution}

Mean weight diameter (MWD) of soil aggregates in different treatments was measured and analyzed and is presented in Table 4. It is in the order of $\mathrm{MWD}_{\text {dry }}>$ $\mathrm{MWD}_{2}>\mathrm{MWD}_{50}>\mathrm{MWD}_{\text {wet }}$, indicating that the aggregates in the slow wetting treatment, $\mathrm{MWD}_{2}$ (weight diameter of wetting rate $2 \mathrm{~mm} \mathrm{~h}^{-1}$ ), had higher stability than those in the fast wetting treatment, $\mathrm{MWD}_{50}$ (weight diameter of wetting rate $50 \mathrm{~mm} \mathrm{~h}^{-1}$ ). For the same soil type, the difference in stability of aggregates was determined mainly by dissipation of water in soil, that is, their stability was weakened while the dissipation was enhanced.
Fig. 4 Bulk density $\left(10^{3}\right.$ $\mathrm{kg} \mathrm{m}^{-3}$ ) and cumulative infiltration $(\mathrm{ml})$ under different wetting rate during rainfall. Each data show the means of four replicates, and the error bar represents the standard error
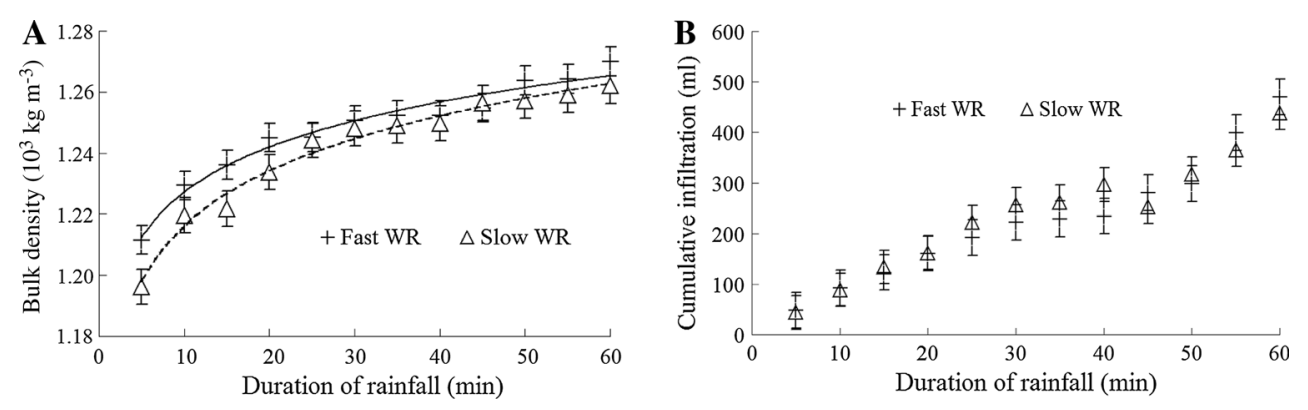
Table 4 Mean weight diameter of soil aggregates in different treatments

\begin{tabular}{llll}
\hline MWD $_{\text {wet }}$ & MWD $_{50}$ & MWD $_{2}$ & MWD $_{\text {dry }}$ \\
\hline $0.58 \pm 0.01$ & $0.90 \pm 0.02$ & $1.07 \pm 0.03$ & $1.20 \pm 0.02$
\end{tabular}

\pm Standard deviation, 4 replications, $n=4$

$M W D_{\text {wet }}$ weight diameter of wet soil, $M W D_{50}$ weight diameter of fast wetting $\left(50 \mathrm{~mm} \mathrm{~h}^{-1}\right)$ soil, $M W D_{2}$ weight diameter of slow wetting $\left(2 \mathrm{~mm} \mathrm{~h}^{-1}\right)$ soil, $M W D_{d r y}$ weight diameter of dry soil

High energy was involved in the disintegration of stable aggregates in the fast wetting process. A greater quantity of finer materials were produced from the disintegrated aggregates at the soil surface in the fast wetting treatment, and were continued to be compacted, which increased the cohesion force between soil particles and led to an increase in soil strength. Conversely for the slow wetting treatment, there was less effect because of more limited supply of finer materials and because of the continued presence of larger and more stable aggregates that resisted breakdown and compaction due to raindrop impact. This would confirm the explanation, as suggested above, that the crust strength of the soil pretreated by slow wetting is weaker than that in the fast wetting case to the end of the rainfall event due to the persistent presence of stable aggregates, albeit microaggregates, and, consequently, reduced levels of compaction.

\section{Saturated and unsaturated soils}

Soil moisture saturation is crucial for the formation of crusts. Soil in this study is saturated soil, so the main conclusion of the study is only applicable to saturated soil. In reality, only when soil is fully saturated and runoff is formed, will the physical crusts produced have approximate results as this experiment. The process of crust formation in an unsaturated condition is relatively complicated and is hard to control, so study on crusts in unsaturated case was not involved in this experiment.

\section{Conclusions}

The characteristics of crusts are closed related to soil erosion in red loam under a rainfall condition. Wetting rate is an important factor influencing soil aggregate stability and crust formation. In this study, crust formation-destructionformation process appeared sharp in the fast wetting treatment but gentle in the slow fast wetting treatment. Surface morphology and profile microstructure show that crusts were formed earlier in the fast wetting treatment. In a rainfall condition, soil in the fast wetting treatment had higher bulk density, stronger crust strength and lower infiltration rate. Therefore, the fast wetting treatment had higher ability to resist the damage caused by raindrops, and the ability to resist soil erosion and increase runoff rate in the fast wetting treatment is higher than that in the slow wetting treatment. Soil in this study is saturated soil, so the main conclusion of the study is only applicable to saturated soil. In reality, only when soil is fully saturated and runoff is formed, will the physical crusts produced have approximate results as this experiment.

Acknowledgments Funding for this work was supported by the National Natural Science Foundation of China (Grant No. 51309008) and by the Fundamental Research Funds for the Central Universities (No. TD 2011-01).

\section{References}

Adriano DC (2001) Trace elements in terrestrial environments: biogeochemistry, bioavailability, and risk of metals, 2nd edn. Springer-Verlag, New York

Agassi M, Morin J, Shainberg I (1985) Effect of raindrop impact energy and water salinity on infiltration rates of sodic soils. Soil Sci Soc Am J 49:186-190

Alary K, Babre D, Caner L, Feder F, Szwarc M, Naudan M, Bourgeon G (2013) Pretreatment of soil samples rich in short-range-order minerals before particle-size analysis by the pipette method. Pedosphere 23:20-28

Al-Durrah MM, Bradford JM (1981) New methods of studying soil detachment due to water drop impact. Soil Sci Soc Am J 45:949-953

Asadi H, Ghadiri H, Rose CW, Rouhipour H (2007) Interrill soil erosion processes and their interaction on low slopes. Earth Surf Proc Land 32:711-724

Assouline S (2004) Rainfall-induced soil surface sealing: a critical review of observation of clay suspensions. Soil Sci 127:134-139

Betzalel I, Morin J, Benyamini Y, Agassi M, Shainberg I (1995) Water drop energy and soil seal properties. Soil Sci 159:13-22

Bissonnais YL, Arrouays D (1997) Aggregate stability and assessment of soil crustability and erodibility: II. Application to humic loamy soils with various organic carbon contents. Eur J Soil Sci 48:39-48

Bradford JM, Huang CH (1992) Mechanisms of crust formation: physical components. Advances in soil science. Soil crusting: physical and chemical processes. Lewis Publishers, Boca Raton

Bradford JM, Ferris JE, Remley PA (1987) Interrill soil erosion processes: I. Effect of surface sealing on infiltration, runoff, and soil splash detachment. Soil Sci Soc Am J 51:1566-1571

Brown LC, Foster GR (1987) Storm erosivity using idealized intensity distributions. Trans ASAE Am Soc Agri Eng 30:379-386

Buol SW, Southard RJ, Graham RC et al (2011) US soil taxonomy. Soil genesis and classification, 6th edn, pp 207-232

Campbell DJ (1976) Plastic determination using a drop cone penetrometer. J Soil Sci 27:295-300

Chen Y, Tarchitzky J, Brouwer J, Morin J, Banin A (1980) Scanning electron microscope observations on soil crusts and their formation. Soil Sci 130:49-55

Cheng YZ (1990) On the law of soil erosion on the Loess Plateau in west of Shanxi Province. China Water Power Press, Beijing, China, Beijing (in Chinese)

Cooperative Research Group on Chinese Soil Taxonomy (2001) Chinese Soil Taxonomy. Sciences Press, Beijing (in Chinese) 
Cresswell HP, Hamilton (2002) Particle size analysis. In: McKenzie NJ, Cresswell HP, Coughlan KJ (eds) Soil physical measurement and interpretation for land evaluation. CSIRO Publishing, Collingwood

Eldridge DJ, Greene RSB (1994) Microbiotic soil crusts-a review of their roles in soil and ecological processes in the rangelands of Australia. Soil Research 32:389-415

Eldridge J, Leys JF (2002) Exploring some relationships between biological soil crusts, soil aggregation and wind erosion. J Arid Environ 53:457-466

Eltaif NI, Gharaibeh MA (2008) Impact of alum on crust prevention and aggregation of calcareous soil: laboratory studies. Soil Use Manag 24:424-426

Fan H, Cai Q, Cheng G (2005) Comparative study of the soil erosion and control in the three major black soil regions in the world. Journal Nature Resource 3:387-393 (in Chinese)

Fan Y, Lei T, Shainberg I, Cai Q (2008) Wetting rate and rain depth effects on crust strength and micromorphology. Soil Sci Soc Am J 72:1604-1610

FAO (1998) World Reference Base for Soil Resources. Food and Agriculture Organization of the United Nations, Rome

Grossman RB, Reinsch TG (2002) SSSA book series: 5 methods of soil analysis, 2nd edn. In: Dane JH, Clarke Topp G (eds) Soil Science Society of America, Inc., Madison

Hartemink AE, Hempel J, Mcbratney A, Mckenzie N, Macmillan RA, Minasny B (2010) A New Digital Soil Map of the World. Digital Soil Mapping:bridging Research, Environmental Applications \& separation/Boettinger, J 325:423-428

Hu X, Liu LY, Li SJ, Cai QG, Lu YL, Guo JR (2012) Development of Soil Crusts Under Simulated Rainfall and Crust Formation on a Loess Soil as Influenced by Polyacrylamide. Pedosphere 22:415-424

Kemper WD, Koch EJ (1966) Aggregate stability of soils from western United States and Canada: measurement procedure, correlations with soil constituents (No. 1355). Agricultural Research Service, US Department of Agriculture

Kumar S (2003) Effect of different vegetation systems on soil erosion and soil nutrients in red soil region of southeastern China. Pedosphere 13:121-128

Lesschen JP, Kok K, Verburg PH, Cammeraat LH (2007) Identification of vulnerable areas for gully erosion under different scenarios of land abandonment in Southeast Spain. Catena $71: 110-121$

Levy GJ, Mamedov AI (2002) High-energy-moisture-characteristics aggregate stability as a predictor for seal formation. Soil Sci Soc Am J 66:1603-1609

Loch RJ (1994) Structure breakdown on wetting. Sealing, rusting and hard setting soils. Australian Soil Science Society Queensland Press, Brisbane
Luk SH, Cai QG (1990) Laboratory experiments on crust development and rainsplash erosion of loess soils, China. Catena 17:261-276

McIntyre DS (1958) Permeability measurements of soil crusts formed by raindrop impact. Soil Sci $85: 185-189$

Moore ID (1980) Effect of surface sealing on infiltration. ASAE, pp 80-2524

Morgan RPC (1978) Field studies of rainsplash erosion. Earth Surf Proc Land 3:295-299

Morin J, Winkel JV (1996) The effect of raindrop impact and sheet erosion on infiltration rate and crust formation. Soil Sci Soc Am J 60:1223-1227

Narayana DVV, Babu R (1983) Estimation of soil erosion in India. Journal of Irrigation and Drainage Engineering 109:419-434 (in Chinese)

Nciizah AD, Wakindiki IIC (2014) Rainfall pattern effects on crusting, infiltration and erodibility in some South African soils with various texture and mineralogy. Water SA 40:57-63

Norton LD (1987) Micromorphological study of surface seals developed under simulated rainfall. Geoderma 40:127-140

Pathak P, Sudi R, Wani SP, Sahrawat KL (2013) Hydrological behavior of Alfisols and Vertisols in the semi-arid zone: implications for soil and water management. Agric Water Manag 118:12-21

Saleh A (1993) Soil aggregate and crust density prediction. Soil Sci Soc Am J 52:524-526

Shainberg I, Levy GJ (1992) Physico-chemical effects of salts upon infiltration and water movement in soils. In: Wagenet RJ, Baveye P, Stewart BA (eds) Interacting processes in soil science. Lewis Publishers, Boca Raton

Shainberg I, Mamedov AI, Levy GJ (2003) The role of wetting rate and rain energy in seal formation and interrill erosion. Soil Sci 168:54-62

Towner GW (1973) An examination of the fall-cone method for the determination of some strength properties of remoulded agricultural soils. Journal Soil Science 24:470-479

United States Department of Agriculture (1996) Soil survey laboratory methods manual (version 3.0). Soil investigation report no. 42, USA Government Print, Washington, DC

Wakindiki IIC, Ben-Hur M (2002) Soil mineralogy and texture effects on crust micromorphology, infiltration, and erosion. Soil Sci Soc Am J 66(3):897-905

Wang QR, Li YC, Klassen W (2005) Determination of cation exchange capacity on low to highly calcareous soils. Commun Soil Sci Plant Anal 36:1479-1498 (in Chinese)

Zhang B, Horn R (2001) Mechanisms of aggregate stabilization in Ultisols from subtropical China. Geoderma 99:123-145 